\title{
A oscilação do preço do petróleo: uma análise sobre o período entre 2010-2015
}

\section{The oscillation of oil price: an analysis of the period between 2010-2015}

DOI: 10.5752/P.2317-773X.2017v6.n1.p87

Recebido em: 1010412018

Aprovado em: 10104|2018

\author{
Cássio Garcia Ribeiro ${ }^{1}$ \\ Henrique Belluzzo Alba Neto² \\ Túlio Silva Sene ${ }^{3}$
}

\section{Resumo}

Apesar da importância crescente de outras fontes energéticas ao longo das últimas décadas, como das chamadas "fontes renováveis", o petróleo se manteve como principal fonte da matriz energética mundial. Diante do papel desempenhando por essa commodity para a economia mundial, este trabalho buscou averiguar os principais elementos desencadeadores das oscilações no preço do barril do petróleo, com o objetivo de abrir a caixa preta do contrachoque que ocorreu a partir de 2014. A metodologia adotada se apoiou em análise bibliográfica, pesquisa documental e coleta de dados secundários. A principal conclusão que se extrai deste estudo é a de que o preço do petróleo oscila em função de três variáveis fundamentais, quais sejam: oferta versus demanda, questões geopolíticas e mercado financeiro. A oscilação no sistema de preços do barril de petróleo é influenciada por estes fatores ao mesmo tempo em que os influencia em um processo de retroalimentação. Nesse sentido, estudos apoiados exclusivamente nos movimentos do mercado (isto é, em flutuações na oferta e na demanda) são insuficientes para explicar os choques e contrachoques no preço do petróleo.

Palavras-chave: Petróleo; Geopolítica; Preço; Contrachoque.

\begin{abstract}
Despite the growing importance of other energy sources over the last decades, as of the so-called "renewable sources", oil has remained the main source of the world energy matrix. Given the role played by this commodity for the world economy, this work sought to ascertain the main triggers of oil price fluctuations, with the objective of opening the black box of the counterbalance that occurred from 2014. the methodology employed in this study is based on bibliographic analysis, documentary research and secondary data collection. The main conclusion drawn from this study is that the price of oil fluctuates according to three fundamental variables: supply versus demand, geopolitical issues, and the financial market. The oscillation in the oil barrel price system is influenced by these factors at the same time as it influences them in a feedback process. In this sense, studies based exclusively on market movements (ie, fluctuations in supply and demand) are insufficient to explain the shocks and counter-shock in the price of oil.
\end{abstract}

1. Doutor em Política Científica e Tecnológica pela Universidade Estadual de Campinas (2009). Atualmente é professor do Instituto de Economia e Relações Internacionais (IERI) da Universidade Federal de Uberlândia (UFU), onde atua na graduação e na pós-graduação em Economia. Sua agenda de pesquisa esta centrada principalmente nos temas do desenvolvimento e da inovação tecnológica, com ênfase nas seguintes áreas: política industrial, política de Ciência, Tecnologia e Inovação, política de compras governamentais, estudos setoriais (petróleo, energia e aeronáutico) e Petrobras. Orcid: 0000-0001-9290-0660

2. Possui graduação em Relações Internacionais pela Universidade Federal de Uberlândia (2016). Foi membro da área de intercâmbios profissionais para empresas, da organização internacional AIESEC. Foi bolsista de iniciação científica com fomento do Conselho Nacional de Desenvolvimento Científico e Tecnológico (CNPq), desenvolvendo uma pesquisa acerca da geopolítica do petróleo no século XXI e seus rebatimentos sobre a dinâmica do preço internacional dessa commodity. Orcid: 0000-0001-9692-6083

3. Doutor em Economia Política Internacional pela Universidade Federal do Rio de Janeiro (UFRJ). Possui graduação em Ciências Sociais, com habilitação em Sociologia e Política, pela Universidade Estadual de Campinas (UNICAMP). Atualmente é professor substituto no curso de Bacharelado em Relações Internacionais da Universidade Federal de Uberlândia (UFU), onde pesquisa as relações internacionais de poder e 0 sistema interestatal, com ênfase nos desafios e limites do intercâmbio global de ciência e tecnologia. Em 2013/14 foi pesquisador visitante na Universidade de Columbia em Nova lorque e, no último trimestre de 2012, completou, com êxito, o Programa de Capacitação Acadêmica e Pesquisa da Missão Permanente do Brasil junto às Nações Unidas, também na cidade de Nova Iorque. Orcid: 0000-0003-1933-9322

Key-words: Oil, Geopolitics; Price; Counter-shock. 
Introdução

A emergência do petróleo como matéria-prima indispensável, particularmente após a Segunda Guerra Mundial, fez com que esse recurso fosse considerado não apenas necessário ao desenvolvimento industrial e econômico dos Estados nacionais, como também estratégico para o fortalecimento político das nações. O Petróleo e outros combustíveis líquidos, apesar de terem diminuído sua participação na matriz energética mundial, mantiveram seu predomínio, contribuindo com cerca de $35 \%$ da energia consumida pelo mundo. Ademais, cumpre ressaltar a importância do petróleo para mover as máquinas militares. Nesse sentido, independentemente da eventual queda em sua de participação na matriz energética mundial, estamos diante de uma fonte de energia extremamente estratégica para os países.

Sobretudo após a revolução industrial, a energia assumiu papel de relevo como vetor básico do crescimento dos países, contribuindo para o surgimento de uma geopolítica internacional extremamente truncada e turbulenta, que já culminou em diversas disputas por interesses de produção e domínio dessa commodity especial. Evidencia-se, portanto, que o seu valor não varia simplesmente em virtude das oscilações na oferta e demanda, como defendem aqueles que advogam em favor da liberdade dos mercados. Por isso, o objetivo do presente artigo é analisar justamente a oscilação no sistema de preços do petróleo buscando identificar alguns fatores que contribuem para a variação nos preços.

Este trabalho se justifica em virtude da importância do petróleo na matriz energética internacional e do papel desempenhado pelo preço do petróleo para a economia mundial (seja para os países importadores, seja para os países produtores de petróleo). Ademais, cabe destacar a pertinência de estudos que se debrucem sobre as oscilações abruptas no preço do petróleo a partir dos anos de 2014 e 2015, ainda pouco explorado pela literatura, justamente por se tratar de um fenômeno recente.

Para compreender esse contrachoque recente é importante investigar o período que o antecede, o que justifica a escolha de um recorte temporal mais amplo que vai de 2010 a 2015. Assim, partindo de um recorte temporal que vai de 2010 a 2015, buscamos elucidar os determinantes do contrachoque recente no preço dessa commodity. A hipótese defendida neste trabalho, a partir da análise da literatura especializada e dos dados sobre o setor petrolífero que serão apresentados ao longo das próximas seções é a de que as oscilações no preço do petróleo são resultados das seguintes forças: oferta versus demanda, questões geopolíticas e financeirização do petróleo.

Esta pesquisa comportará os seguintes procedimentos metodológicos: pesquisa bibliográfica, pesquisa documental e coleta e processamento de dados secundários. A pesquisa bibliográfica adotada neste trabalho se apoiará na revisão de trabalhos acadêmicos que abordam o mercado petrolífero e a geopolítica do petróleo no século XXI, enfatizando atores principais, estratégias, conflitos de interesse etc. No que diz respeito à pesquisa documental adotada neste estudo, ele abarcará o levantamento sistemático de documentos (como relatórios anuais, boletins, notas téc- 
nicas, artigos, tabelas, quadros etc.) disponibilizados nas homepages da Energy Information Administration (EIA), British Petroleum (BP), Intercontinental Exchange (ICE) e de revistas e periódicos nacionais e internacionais especializados em petróleo e gás.

Em relação à coleta de dados, este estudo se apoia também em dados secundários (séries temporais e estatísticas) sobre o setor petrolífero. Esses dados servirão de referência para que se obtenha rigor e embasamento estatístico das informações apresentadas, tornando possível que se sistematize uma série de informações quantificáveis, tais como: flutuações no preço do barril do petróleo; comportamento da oferta e da demanda mundial de hidrocarbonetos; produção convencional versus não-convencional com dados pormenorizados por regiões e países principais; movimentos especulativos em torno do preço do petróleo (contratos $s p o t^{4}$ e futuro de compra e venda de petróleo). Esta pesquisa se apoiará nas seguintes bases de dados: EIA (Annual Energy Outlook) e British Petroleum (BP Statistical Review of World Energy - BP Global) e ICE.

Este artigo conta com outras quatro seções, além da introdução. $\mathrm{O}$ objetivo da segunda seção é discutir qual papel a interação entre oferta versus demanda por petróleo exercem sobre o preço desse hidrocarboneto, destacando o período recente. Na terceira seção o foco se dirige à geopolítica do petróleo. A financeirização do petróleo é abordada na quarta seção. Na quinta seção são apresentadas as principais conclusões extraídas a partir da realização deste estudo.

A oscilação no preço do petróleo e o papel exercido pelas forças da oferta e demanda

A volatilidade do preço do petróleo é uma característica marcante do mercado desse hidrocarboneto, especialmente a partir dos choques do petróleo que ocorreram na década de 1970. No primeiro choque, em 1973, houve um aumento de cerca de $400 \%$ no preço do barril do petróleo, quando o preço saltou de US\$ 2,90 para US\$ 11,65 em apenas três meses. Em 1979, quando ocorre o segundo choque, o preço do barril passa a ser vendido a US\$31,61. Já na década seguinte, observa-se um movimento de refluxo nos preços: a cotação do barril do petróleo tipo Brent entre 1985 e 1986 , sofre uma queda acentuada (de US\$27,56 para US\$14,43), fenômeno que foi cunhado pela literatura especializada de contrachoque no preço do petróleo (Pinto Jr. et al., 2007).

Calculando a média e o desvio padrão do intervalo temporal de 1990 até 2016 (valores corrigidos a preços de 2016), verificamos que a média é de 56,58 com desvio padrão 32,30, considerado alto, o que corrobora a hipótese de que o preço dessa commodity se comporta de maneira instável (Pinto Jr. et al., 2007). O gráfico 1 ilustra a dispersão dos preços do petróleo, demonstrando o quão voláteis se comportaram tais preços entre o final do século XX e início do século XXI, especialmente se considerarmos os patamares em que se situam os pontos de máximo e mínimo (US\$18,72 e US\$ 118,71 , respectivamente).

A mais recente oscilação significativa ocorreu a partir de 2014. Em fevereiro daquele ano o barril do tipo Brent alcançou o pico de cerca de
4. Preço a vista relacionado pronta entrega da mercadoria. 
US\$ 110 dólares. Todavia, ao longo de 2014 o cenário se modificou drasticamente com o barril de petróleo chegando a ser vendido a US\$ $62 \mathrm{em}$ dezembro. Na Tabela 1, com a extensão da análise para o período que vai de 2010 a 2015, é possível verificar a trajetória do preço (média anual) do petróleo cru e identificar a magnitude da oscilação no preço.

Gráfico 1 - Dispersão do preço do petróleo (1990 - 2015)

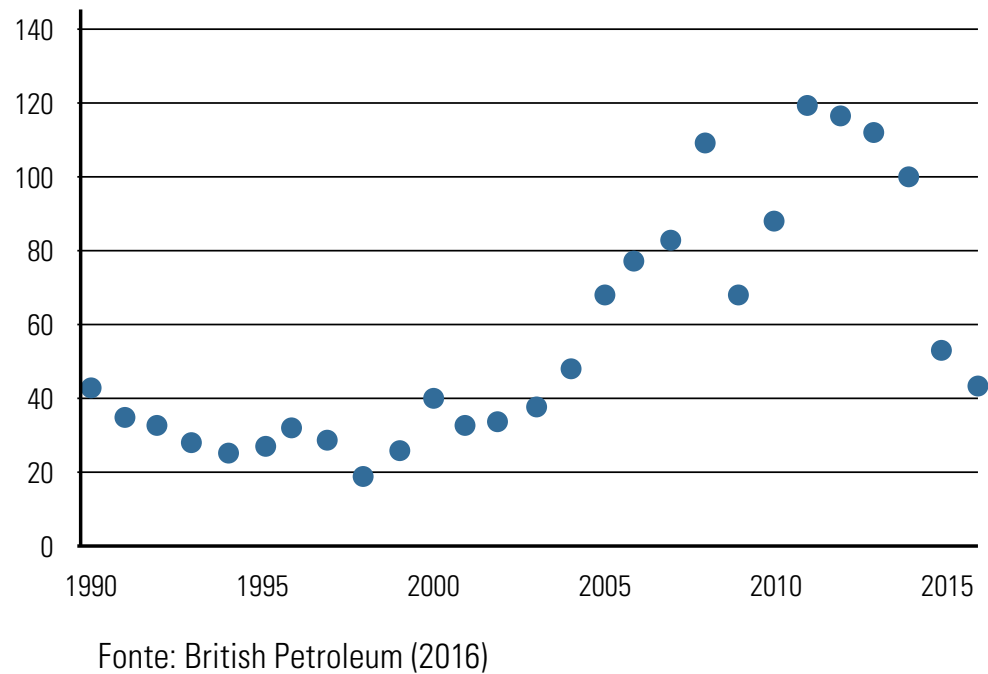

Tabela 1 - Evolução do preço do petróleo cru entre 2010 e 2015

\begin{tabular}{c|c}
\hline Ano & US\$ $(2015=100)$ \\
\hline 2010 & 86,41 \\
\hline 2011 & 117,23 \\
\hline 2012 & 115,28 \\
\hline 2013 & 110,55 \\
\hline 2014 & 99,06 \\
\hline 2015 & 52,39 \\
\hline
\end{tabular}

Fonte: British Petroleum (2016).

A análise da Tabela 1 corrobora o argumento acerca da alta volatilidade do preço do petróleo, sobretudo se considerarmos que os valores estão corrigidos ao longo do período compreendido por este estudo. $\mathrm{O}$ preço médio anual do petróleo variou de um pico US\$117,23 (2011) para um vale de US\$ 52,39 (2015). Em relação à Tabela 1, deve-se destacar a reversão da tendência de alta e a queda abrupta no preço médio do barril de petróleo, particularmente entre 2014 e 2015, período no qual houve um recuo de $47 \%$ nesse valor. Nesse período, o preço do petróleo apresentou o maior declínio já registrado em termos de dólares e a maior queda percentual desde 1986. Em virtude da queda expressiva no valor do barril em um intervalo tão curto de tempo, tal fenômeno foi cunhado de contrachoque no preço do petróleo.

Com o preço do petróleo em alta a partir dos primeiros anos do século XXI, houve um estímulo ao aumento da produção, inclusive dos chamados hidrocarbonetos não-convencionais. A Agência Internacional de Energia define o petróleo convencional em seu World Energy Outlook 
2011 como uma mistura de hidrocarbonetos que existem em fase líquida sob condições normais de superfície. Os óleos não convencionais são definidos como os óleos obtidos por técnicas de produção não convencionais porque não podem ser recuperados através do bombeamento no seu estado natural a partir de um poço de produção normal sem serem aquecidos ou diluídos. O Departamento de Energia dos EUA divide o óleo não convencional em quatro tipos: óleo pesado, óleo ultra-pesado, betume e xisto betuminoso. Alguns analistas também incluem processos de gás para líquidos (GTL) para a conversão de gás natural em petróleo e processos de carvão a líquidos (CTL) para a conversão de carvão em petróleo na categoria de óleos não convencionais. Estas técnicas de processamento de óleo não convencionais ampliam a matéria-prima de óleos não convencionais para incluir gás natural não convencional, tal como gás estanque, gás de xisto, metano de leito de carvão e hidratos de metano.

Portanto, a alta nos preços do petróleo, particularmente entre 2010 e começo de 2014, estimulou a produção não convencional, sobretudo nos Estados Unidos e no Canadá. O governo norte-americano incentivou fortemente a produção "não convencional" de hidrocarbonetos, em especial por meio do fracking ou "hydraulic fracturing", a qual apresenta maiores custos em comparação aos métodos convencionais (ISENMANN, 2014). Apesar de apresentarem custos de produção mais elevados em comparação ao do petróleo convencional, os métodos não-convencionais alcançam viabilidade econômica em um cenário de alta nos preços do barril do petróleo.

Outro aspecto que deve ser mencionado aqui para explicar a tendência de alta no preço do barril de petróleo na primeira parte do período analisado diz respeito ao fato de que a elevação no preço do barril de petróleo incentivou a produção nos países não pertencentes à OPEP. Evidência desse fenômeno é o fato de que na atualidade $60 \%$ da produção total de petróleo pode ser classificada como "não-OPEP". As localidades principais onde se concentram a produção considerada "não-OPEP" são: América do Norte; países que faziam parte da antiga União Soviética (sobretudo a Rússia) e o Mar do Norte. A produção não-OPEP ocorre principalmente em áreas nas quais os custos de descoberta e de produção de petróleo são altos, culminando com uma certa desvantagem destes em relação aos produtores da OPEP, os quais desfrutam de custos de produção mais baixos (EIA, 2016). O gráfico 2 mostra o desenvolvimento da produção dos países pertencentes à OPEP, em comparação com a produção proveniente dos países não-OPEP, de 2010 a 2015.

Portanto, a alta no preço do petróleo até o início de 2014 provocou um excesso de oferta de petróleo no mundo, provocando "sobra" desse recurso no mercado. Como resultado, foi colocada em marcha uma batalha entre os grandes produtores de petróleo para garantir seu volume de vendas. Paralelamente a esse processo, houve um esfriamento da procura em decorrência do desaquecimento da economia mundial pós-crise de 2008 e da crônica fragilidade econômica mundial. A China, por exemplo, apesar de ter mantido seu dinamismo nos primeiros momentos da crise, mostrou-se, posteriormente, fragilizada, apresentando uma queda em sua demanda por petróleo (GHIRARDI, 2014). O gráfico 3 apresenta um balanço entre produção e consumo mundiais de petróleo ao longo do período abarcado por este estudo.
5. 0 fraturamento hidráulico representa uma maneira não convencional de extrair petróleo de ambientes profundos, o qual se intercala em rochas porosas e sedimentos naturais. 
Gráfico 2 - OPEP vs não-OPEP (2005 - 2015): participação na produção petrolífera mundial

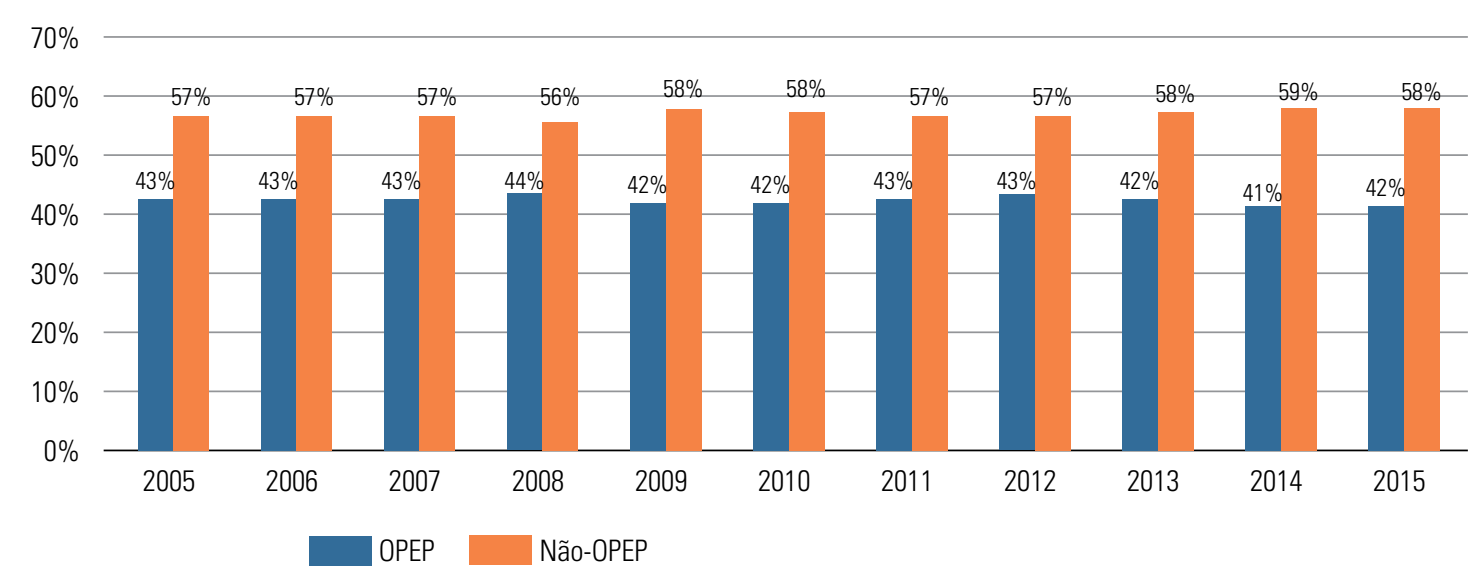

Fonte: EIA (2016).

Gráfico 3 - Produção e consumo mundiais de petróleo entre 2010 e 2015

(milhões de barris por dia)

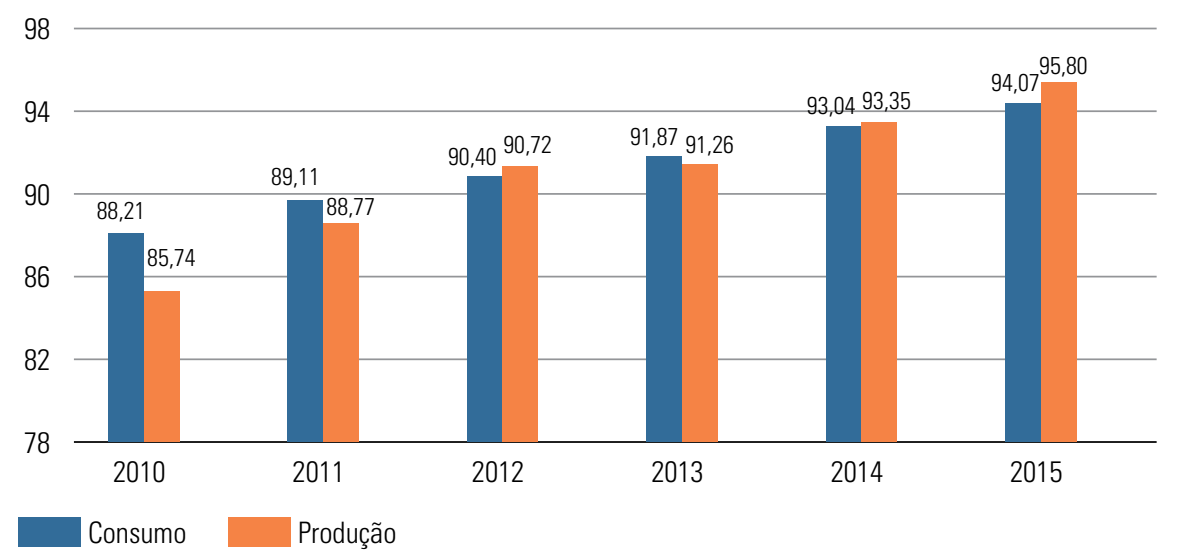

Fonte: EIA (2016).

O gráfico 3 revela que no começo da década de 2010 o consumo se posicionava em um patamar mais elevado comparativamente à produção. Todavia, a partir de 2014 essa tendência se inverte. Cabe destacar que as condições de oferta e de demanda observadas no mercado internacional do petróleo não obedecem apenas à evolução das decisões de investimento das companhias de petróleo na produção de petróleo bruto. Há que se considerar também suas inversões direcionadas à expansão e à utilização da capacidade de refino. Nesse sentido, ciclos de ampliação de investimentos em produção e refino podem desencadear uma sobrecapacidade, a depender das condições de demanda.

As unidades de destilação de petróleo ao redor do mundo, que transformam o óleo bruto em combustíveis e químicos, aumentaram a capacidade em 5,89 milhões de barris por dia (bpd) entre 2010 e 2015 (BRITISH PETROLEUM, 2016). A expansão no refino foi puxada principalmente pela China, que acrescentou 3,96 milhões bpd em capacidade entre 2010 e 2015. Tendo em vista o elevado crescimento no refino de petróleo, a capacidade global aumentou acima do crescimento da demanda, o que representou mais um fator a pressionar para baixo a oscilação no preço 
do barril do petróleo a partir de 2014, em virtude da formação de estoques. Assim, a maior produção associada com a diminuição no consumo provocou uma readequação na curva de oferta e demanda forçando os preços na direção do contrachoque atual. Os mecanismos de mercado se mostram, desta forma, fatores relevantes para a análise das oscilações no sistema de preços do petróleo. Entretanto, não são suficientes para um diagnóstico minimamente conclusivo sobre as causas das oscilações no sistema de preços do mercado de petróleo. Muito embora oferta e demanda sejam mecanismos muito relevantes para este tipo de análise, é imprescindível considerar conjuntamente os fatores geopolíticos.

A geopolítica do petróleo

No que diz respeito ao tema da geopolítica do petróleo, para além da busca pela sustentabilidade da matriz energética, encontra-se um emaranhado de objetivos estratégicos, políticos, econômicos e de soberania dos Estados nacionais. Assim, a interligação entre o domínio energético e a concretização do poder no cenário internacional está no cerne desse tema. A ascensão do petróleo como um recurso revolucionário, estratégico e vital, portanto, não apenas transformou toda a lógica energética global, como também afetou profundamente o sistema e as relações entre os países.

Até a primeira metade do século XX, o mercado mundial de petróleo era dominado pelo cartel das "Sete Irmãs"6. Essas empresas possuíam diversas vantagens, como concessões e áreas para exploração, falta de provisão para a devolução de áreas inexploradas, contratos que permitiam fixar termos fiscais, liberdade em suas atividades de exploração, produção, transporte, refino, entre outras. Diante disso, pode-se afirmar que os primórdios da indústria mundial do petróleo (especialmente após a Segunda Guerra Mundial) tem um caráter oligopolista, em um contexto marcado pelo predomínio das "Sete Irmãs" (FUSER, 2005).

A partir de 1950, os países consumidores e os países detentores das reservas de petróleo exploradas por concessão pelas majors começam a se mobilizar contra a política de apropriação da renda petrolífera promovida pelo cartel. Além disso, motivações de natureza política, como a autonomia nacional e a responsabilidade quanto ao abastecimento interno, provocaram uma mudança no comportamento dos governos dos países onde se concentrava a produção de petróleo. No bojo desse processo, dá-se início ao surgimento das companhias nacionais de petróleo (National Oil Companies - NOCs ${ }^{7}$ ). A onda de nacionalizações, que teve início após a Segunda Guerra Mundial e se estendeu até a década de 1970, pode ser entendida como um ponto crucial no processo de reestruturação pelo qual passou a indústria do petróleo. Assim, o o petróleo se transformou em elemento central nas estratégias e agendas elaboradas com vistas à promoção do desenvolvimento de regiões que disfrutavam da presença de grandes reservas (YERGIN, 1993).

A diminuição do poderio das Sete Irmãs pode ser considerada como a consequência principal desse processo de nacionalizações. Os preços se encontravam em estado relativamente estável, em patamares reduzidos,
6. 0 cartel das "Sete Irmãs" era formado pelas "cinco grandes empresas petroleiras norte-americanas em operação no cenário internacional: a Exxon (ou Jersey), a Mobil, a Standard Oil of California (SoCal), a Texaco e a Gulf. Somadas às européias Shell e Anglo-Persian (depois Anglo-Iranian, atual British Petroleum), elas formaram um cartel conhecido como 'As Sete Irmãs', ou majors, que dominou o mercado mundial de petróleo até o início da década de 1970. 0 que as atraía a operar no exterior eram, sobretudo, os lucros fabulosos proporcionados pela venda do petróleo estrangeiro" (FUSER, 2005, p. 89)

7. As NOCs são empresas cuja maior parte de suas ações são controladas por governos locais. Entre as NOCs de maior sucesso no setor petrolífero mundial é possível destacar as seguintes: Saudi Aramco (a maior empresa integrada de petróleo e gás do mundo, da Arábia Saudita); a Petrobras; a Petronas (Malásia); a Gazprom (Rússia); a NIOC (Irã); a CNPC (China) e; a PDVSA (Venezuela). Atualmente as NOCs são as principais responsáveis pela produção de petróleo no mundo e suas reservas são superiores àquelas detidas pelas chamadas International Oil Companies (IOCs), tais como a Chevron, a British Petroleum, a ExxonMobil e Shell (WORLD ENERGY COUNCIL, 2016). 
8. Em 1980, portanto, sob o efeito do segundo choque do petróleo, o presidente norte-americano à época, "declarou que qualquer tentativa de restringir o fluxo de petróleo pelo Golfo Pérsico ‘será repelida por todos os meios necessários inclusive a força'" (FUSER, 2005, p. 39). enquanto o cartel detinha o domínio da produção (PINTO JUNIOR e NUNES, 1998). Como reação a esse quadro de desvalorização do preço do petróleo cinco países - Arábia Saudita, Irã, Iraque, Venezuela e Kuwait - que representavam $80 \%$ das exportações mundiais, fundaram a Organização dos Países Exportadores de Petróleo (OPEP), em 14 de setembro de 1960 (TORRES FILHO, 2004). Os representantes desses Estados reuniram-se em Bagdá, para formar essa organização, criada com a finalidade de enfrentar as majors do setor, defendendo os países-membros das práticas de preço impostas pelas companhias internacionais. Assim, a OPEP passa a atuar como um cartel, controlando a produção, com o objetivo de mudar os níveis de preços internacionais de acordo com seus interesses (PINTO JUNIOR e NUNES, 1998). Os dois choques do petróleo evidenciam o sucesso da estratégia levada a cabo por tal organização.

Além da OPEP, é importante destacar neste artigo o papel desempenhado pelos Estados Unidos, player protagonista no tabuleiro da geopolítica do petróleo e principal mercado consumidor desse hidrocarboneto. De acordo com Klare (2009) o suprimento seguro de petróleo, peça-chave da política externa norte-americana desde a segunda Guerra Mundial, foi chancelado a partir da Doutrina Carter ${ }^{8}$. Já no século XXI, durante o governo George W. Bush, presidente dos Estados Unidos entre 2001 e 2009, tal tema continuava a assumir papel estratégico dentro da política externa do país, o que fica evidente a partir da invasão do Iraque.

Pode-se afirmar que o período compreendido pela segunda metade do século XX caracteriza-se por uma geopolítica bastante conturbada em relação ao domínio e à produção de petróleo, muitas vezes se materializando em confrontos violentos. A contraposição de forças políticas e dos interesses dos grandes atores envolvidos nesse cenário ficou evidente. Como exemplo, é possível recuperar a pressão anglo-americana pela saída das tropas soviéticas dos campos de petróleo no Irã durante a Guerra Fria, além da própria Revolução Iraniana de 1979, da invasão do Kuwait em 1991, da "Guerra contra o terror" no Iraque. Todos esses acontecimentos históricos são exemplos claros da dimensão que assume o conflito geopolítico internacional quando se trata de segurança energética e do controle estratégico sobre as principais regiões produtoras de petróleo (YERGIN, 1993; KLARE, 2009).

Ainda em relação ao protagonismo norte-americano na geopolítica do petróleo, é importante lembrar que a derrocada do sistema de Bretton Woods, mais precisamente do padrão dólar-ouro, deu ensejo a uma acentuada elevação nos preços das matérias-primas nos mercados internacionais. Logo, pode-se afirmar que a política macroeconômica norte-americana nos anos 1970, marcada pelo fim da conversibilidade do dólar e a adoção do novo regime de câmbio flutuante (que perdura até os dias de hoje), deu ensejo ao cenário de intensa volatilidade nos preços das commodities internacionais (SERRANO, 2004).

Ademais, particularmente em relação ao setor petrolífero, é importante destacar o papel desempenhado pela política de segurança energética em vigor nos Estados Unidos durante os anos 1970. Antes do primeiro choque, mais precisamente em agosto de 1973, o governo norte-americano apostou na ampliação da exploração do petróleo em território norte- 
-americanos, de modo a reduzir os impactos sobre a economia doméstica decorrentes da alta no preço ${ }^{9}$. Assim, duas medidas foram tomadas no âmbito da política de segurança energética norte-americana, em agosto de 1973: i) o congelamento do petróleo doméstico extraídos dos poços antigos, de modo a não permitir a exploração predatória; ii) a liberalização do preço do petróleo proveniente dos novos poços, com vistas os investimentos nestes últimos. Paralelamente, para impedir o desabastecimento de sua economia, o governo do país aboliu as cotas oficiais de importação de petróleo. O reflexo dessa última estratégia foi o aumento imediato da demanda por barris de petróleo oriundos dos países da OPEP. A deflagração da guerra do Yon Kippur, em outubro de 1973, entre países árabes e Israel, foi um ingrediente que faltava para o primeiro choque do petróleo. De acordo com Serrano (2004, p. 20):

\begin{abstract}
Desta forma, o primeiro choque do petróleo, embora representasse uma situação de relativa perda de controle - sendo sem dúvida resultado direto do conflito distributivo entre os países produtores e os países desenvolvidos, num contexto de questionamento da liderança americana - só teve um efeito de tal magnitude devido à política macroeconômica expansionista dos EUA e, especialmente, à sua nova política de segurança energético.
\end{abstract}

É possível afirmar que os Estados Unidos continuam a exercer o papel de ator protagonista no tabuleiro da geopolítica internacional neste início do século XXI. Eles não apenas continuam como os maiores consumidores de energia do mundo, como também se apresentam como os maiores produtores na atualidade. A tabela 2 mostra a produção de petróleo dos principais países ao longo do período examinado neste estudo, revelando a proeminência norte-americana atual.

Tabela 2 - Produção de petróleo e outros líquidos por país (em milhões de barris por dia)

\begin{tabular}{c|c|c|c|c|c|c}
\hline País/Ano & $\mathbf{2 0 1 0}$ & $\mathbf{2 0 1 1}$ & $\mathbf{2 0 1 2}$ & $\mathbf{2 0 1 3}$ & $\mathbf{2 0 1 4}$ & $\mathbf{2 0 1 5}$ \\
\hline Irã & 4,25 & 4,22 & 3,52 & 3,19 & 3,38 & 3,48 \\
\hline Iraque & 2,64 & 2,62 & 2,98 & 3,05 & 3,38 & 4,05 \\
\hline Kuwait & 2,45 & 2,68 & 2,78 & 2,80 & 2,77 & 2,71 \\
\hline Arábia Saudita & 10,91 & 11,47 & 11,84 & 11,70 & 11,61 & 11,95 \\
\hline China & 4,38 & 4,39 & 4,46 & 4,57 & 4,30 & 4,72 \\
\hline Rússia & 10,28 & 10,40 & 10,59 & 10,76 & 10,83 & 11,04 \\
\hline Canadá & 3,44 & 3,6 & 3,86 & 4,07 & 4,39 & 4,51 \\
\hline Brasil & 2,72 & 2,7 & 2,67 & 2,71 & 2,97 & 3,19 \\
\hline EUA & 9,69 & 10,13 & 11,11 & 12,37 & 14,02 & 15,12 \\
\hline Total mundial & 85,74 & 88,77 & 90,72 & 91,26 & 93,35 & 95,80 \\
\hline
\end{tabular}

Fonte: EIA (2016)

Em relação aos dados apresentados na Tabela 2, deve-se destacar que em 2010 os Estados Unidos eram o terceiro maior produtor do petróleo cru do mundo, atrás da Arábia Saudita e da Rússia. Em 2013, no entanto, esse cenário se modifica, com os Estados Unidos assumindo a dianteira desse ranking. Portanto, esses dados apontam para uma diminuição da dependência dos Estados Unidos em relação ao petróleo importado, o que traz importantes desdobramentos sobre a geopolítica do petróleo. Ademais, a partir da Tabela 2 é possível identificar outro fenômeno importante: a ma-
9. De acordo com Serrano (2004, p. 20), "A partir de 1971, a OPEP passou a pressionar por reajustes no preço internacional do petróleo e maior participação nos royalties, que estavam muito defasados em termos reais. Considerações sobre a manutenção de boas relações com os países árabes numa área de grandes tensões geopolíticas, a preocupação com a segurança energética e com a viabilidade econômica da indústria petrolífera americana (cujos custos haviam subido muito com a inflação acumulada) levaram os EUA a aceitar reajustes de cerca de $50 \%$ do preço internacional do petróleo de 1971 a 1973". 
nutenção da produção da Arábia Saudita (principal país ligado à OPEP) e da Rússia (principal produtor fora da OPEP) em patamares elevados.

Desta forma, discutir a geopolítica do petróleo como fator relevante para a oscilação nos preços da commodity no mercado internacional exige alguns breves comentários sobre esses três principais estados concorrentes. Começando pelos Estados Unidos, chegamos à conclusão de que eles ainda possuem os elementos que servem de parâmetro para caracterizar a supremacia do poder internacional. Tal país representa não apenas o maior produtor de petróleo, como também tem conseguido diversificar a sua produção, contam com um histórico de intervenções militares em regiões estratégicas para a exploração do petróleo, tem capacidade de mobilização de recursos, possuem uma eficiente máquina burocrática e dominam o discurso. Ao examinarmos o Gráfico 4, por exemplo, é possível observar que, partindo de uma participação marginal na produção total do país em 2000, o óleo cru advindo de poços hidraulicamente fraturados alcançou em 2015 a liderança no total de petróleo produzido nos Estados Unidos. De acordo com o relatório da EIA (2016), cerca de 4,9 milhões de barris por dia de petróleo cru foram produzidos por meio do fracking nos Estados Unidos em 2015, ou 51\% da produção de petróleo cru do país.

Gráfico 4 - Produção de petróleo nos Estados Unidos: poços hidraulicamente fraturados vs poços não-hidraulicamente fraturados (2000 - 2015; milhões de barris por dia)

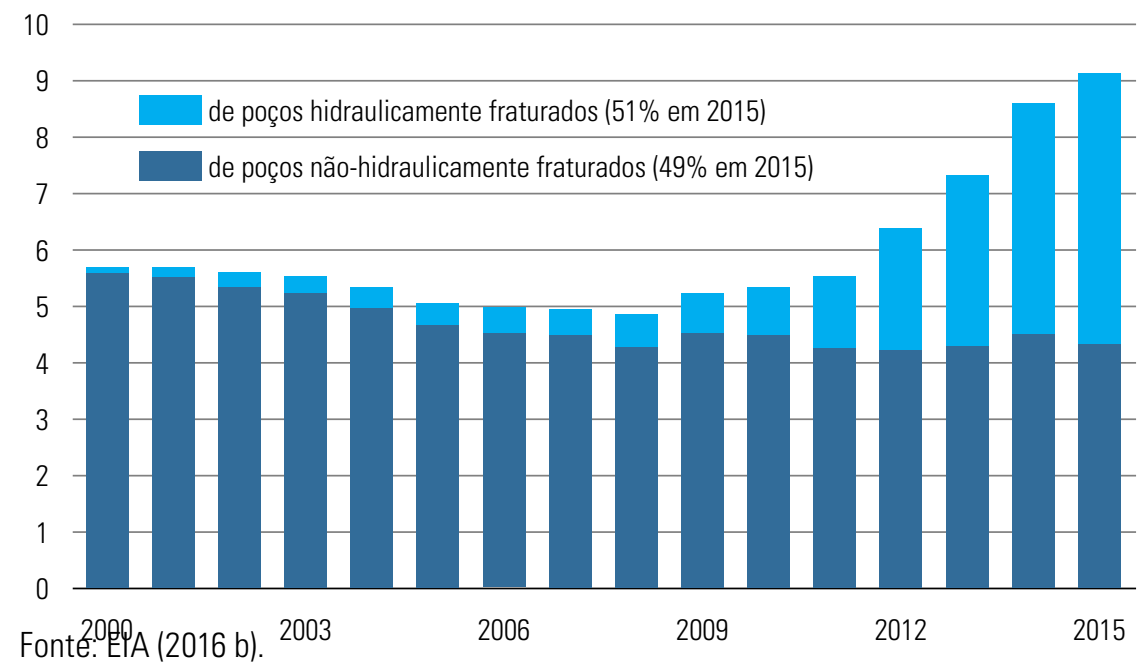

Analisando a produção de petróleo nos Estados Unidos em paralelo com a taxa de consumo, percebe-se que, muito embora o consumo tenha se mantido relativamente estável, a produção aumentou. O Gráfico 5 apresenta dados sobre a produção e o consumo de petróleo nos Estados Unidos entre 2010 e 2015. É possível identificar a partir da análise do Gráfico 5 uma certa estabilidade em relação ao consumo ao longo do período analisado, em cerca de 19 milhões bpd. Todavia, ao contrário, no que concerne à produção de petróleo nos Estados Unidos chama a atenção o crescimento expressivo, passando de 9,7 para 14,02 bpd entre 2010 e 2014 (um crescimento de cerca de $45 \%$ ), convergindo com os dados apresentados no Gráfico 3 acerca do crescimento vertiginoso na produção de petróleo no país por meio do fracking. 
Gráfico 5 - Produção e consumo de petróleo nos Estados Unidos, 2010-2014 (em milhões de barris por dia)

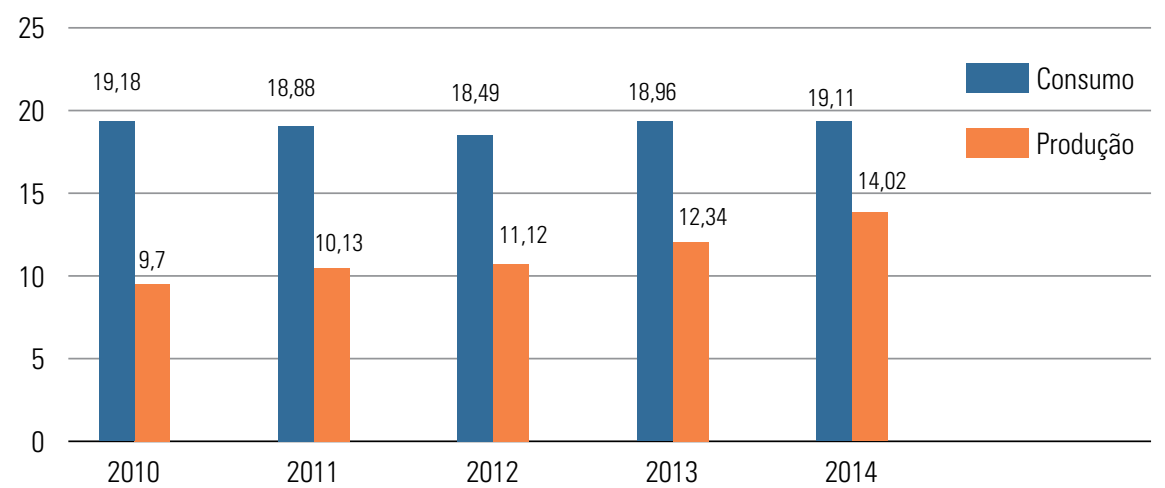

Fonte: EIA (2016).

Considerando a força relativa dos Estados Unidos no cenário internacional e as características da sua produção e consumo, entende-se que o caminho percorrido e as estratégias consideradas pelo seu governo são fundamentais para uma reflexão acerca da geopolítica do petróleo e sua influência sobre a oscilação nos preços de mercado. Em relação às movimentações norte-americanas no tabuleiro da geopolítica do petróleo no século XXI é possível destacar dois elementos centrais: 1) o suprimento petrolífero assume papel de destaque na política externa do país ${ }^{10}$, de modo que o país se dispõe, por intermédio de sua diplomacia, a incentivar reformas de mercado nos países com excesso de produção (EBEL, 2002), bem como utilizar forças militares, se necessário, para garantir o acesso às regiões produtoras, como aconteceu no Iraque (FUSER, 2005); 2) a busca pela diminuição da dependência em relação ao suprimento de hidrocarbonetos provenientes do Oriente Médio, com destaque para o desenvolvimento do método conhecido como "fracking" (de custo mais elevado que o do petróleo "tradicional”), a partir do qual o país conseguiu aumentar significativamente sua produção no período recente (BARROS, 2007a; RAMONET, 2015).

Conforme destacado anteriormente, o argumento defendido neste trabalho é que para compreender as oscilações nos níveis de preços do petróleo não se deve analisar apenas os mecanismos de oferta e demanda, mas também é preciso que se elucide os meandros da geopolítica do petróleo. Nesse sentido, além de considerar que o aumento na oferta mundial decorrente do fracking norte-americano teve implicações sobre o preço no barril do petróleo e que a demanda por petróleo caiu a partir de 2014, é preciso que se leve em conta o papel desempenhado pelos principais governos nacionais concorrentes, como o da Arábia Saudita, que é o país que produz o petróleo mais barato e de melhor qualidade no mundo. Por isso, os sauditas assumiram os papéis de referência no sistema de preços e de "ofertante mundial em última instância" (YERGIN, 2014). Em reunião da OPEP na Áustria, no ano de 2015, o governo da Arábia Saudita não se mostrou preocupado com a queda no preço do petróleo. Ademais, ao contrário do que pretendiam outros países produtores de petróleo que não participam do cartel, como a Rússia e o México, a OPEP decidiu não
10. Em relação ao papel desempenhado pelo petróleo na pauta da política externa norte-americana, cabe observar que o presidente recentemente eleito dos Estados Unidos, Donald Trump, indicou o CEO da ExxonMobil para o cargo de Secretário de Estado no seu governo. Muito embora esse fato fuja do recorte histórico adotado neste artigo, ele ilustra bem a centralidade dessa commodity para a política externa da principal potência mundial. 
reduzir suas metas de produção, o que permitiria que o preço do barril de petróleo voltasse a crescer (LIMA, 2015).

É importante lembrar que o início da trajetória anterior, de elevação no preço do barril de petróleo, deveu-se, em grande medida, aos esforços de Chávez junto aos países-membros da OPEP. Ao assumir a presidência da Venezuela, tal governante se deparou com uma situação econômica grave do país, em decorrência do reduzido preço do barril de petróleo à época (cerca de US\$ 10 em fevereiro de 1999). Dada a alta dependência da economia venezuelana da exportação de petróleo e com vistas a reverter esse quadro, Chávez foi um dos principais mentores da retomada da estratégia da OPEP de valorização do preço do petróleo via controle da oferta. Pode-se afirmar que tal estratégia foi exitosa, pois, em 2001 o preço do barril dessa commodity atingiu o patamar de US\$20 (BARROS, 2007b).

Nesse sentido, cumpre salientar que a opção pela regulação do preço a partir da lógica do mercado, comandada pelos sauditas, representa uma mudança na estratégia tradicionalmente adotada pelo cartel. Até então, sua política hegemônica era manipular o preço do hidrocarboneto, de acordo com seus interesses, mediante o controle da produção (LIMA, 2015). O colapso no preço do petróleo em 1986 e 1998, por exemplo, terminou quando os exportadores de petróleo decidiram reduzir a produção. Todavia, na geopolítica do petróleo no século XXI há forças operando contra essa solução.

A política saudita de manter os preços em níveis reduzidos e de prevenir que eles cheguem a patamares excessivamente elevados serve a seus interesses nacionais, uma vez que os altos preços do petróleo poderiam culminar com o desenvolvimento de fontes de energia alternativas e competitivas, as quais poderiam enfraquecer a relevância energética do petróleo. Caso isso ocorresse, seria extremamente difícil reverter a situação, mesmo se os preços abaixassem posteriormente. Se o valor do petróleo se encontra em nível elevado, isso pode encorajar a exploração do mineral em países fora da OPEP, o que tornaria a competição mais acirrada. Nesse sentido, o preço baixo, mina o desenvolvimento do fracking norte-americano, método cujo custo é mais elevado do que o convencional.

Ademais, o barril do petróleo em patamares reduzidos atinge o Irã, país com o qual a Arábia Saudita mantém uma relação conflituosa (LIMA, 2015). Cabe observar que o acordo nuclear assinado em julho com o governo do Irã trouxe o fim gradual das sanções impostas a tal país. Nesse sentido, a leitura dos demais países do Golfo Pérsico foi a seguinte: cortar sua própria produção de petróleo significa entregar espaço para exportações iranianas adicionais à Ásia e ao noroeste da Europa. Portanto, o governo saudita, ao orquestrar a queda no preço do petróleo busca enfraquecer seu rival regional, o Irã, justamente no momento que em que tal país retorna ao mercado de exportação de petróleo (THE GUARDIAN, 2016). A reentrada do Irã em mercados anteriormente bloqueados ocorre em um momento em que o mercado se encontra saturado (YERGIN, 2016). Ademais, o fim do conflito e os anos de reconstrução trouxeram de volta ao mercado os principais fornecedores de petróleo da Líbia, Argélia e Iraque em 2014. Este último país, praticamente dobrou sua produção 
entre 2010 e 2015, como é possível observar na Tabela 2, ocupando no último ano dessa série, a sexta posição do ranking dos principais países produtores de petróleo do mundo (THERRAMUS e AUSTIN, 2015).

Além dos países árabes, cumpre salientar o importante papel desempenhado pela Rússia na geopolítica do petróleo. Conforme pode-se observar na Tabela 2, o país ocupa a terceira posição do ranking dos maiores produtores de petróleo do mundo. O território russo é extremamente rico em capacidade energética, principalmente devido ao fato da presença de reservas de petróleo e gás natural, criando uma situação de dependência europeia em relação à Rússia (RAFAEL, 2013). Ademais, nas proximidades do território russo, na Ásia Central, há importantes reservas de óleo e gás natural. Isso explica o esforço russo para manter sua influência sobre as ex-repúblicas soviéticas, como o Cazaquistão e o Azerbaijão.

Há uma rivalidade histórica entre Rússia e Arábia Saudita que tem se recrudescido nos últimos anos. Enquanto os sauditas têm sido tradicionalmente o coração pulsante da OPEP, a Rússia, desde a União Soviética, sempre esteve de fora do cartel dos países exportadores de petróleo. Além disso, a Arábia Saudita representa um aliado histórico dos Estados Unidos, o que ajudou a atiçar as tensões entre russos e sauditas ${ }^{11}$. Mais recentemente, a Rússia usou sua proximidade geográfica com a China, país cuja demanda por petróleo cresceu significativamente na última década, para a construção de gasodutos até o território chinês, subtraindo assim uma quota do mercado da Arábia Saudita. Mais recentemente, os dois países assumiram lados opostos na guerra civil da Síria. Enquanto a Arábia Saudita, Estados Unidos e Turquia apoiam as forças oposicionistas, Rússia e Irã, o regime de Bashar al-Assad (HALLIGAN, 2016). Esses e outros elementos concernentes à geopolítica do petróleo nos ajudam a compreender a manutenção da produção russa em patamares elevados, não obstante a queda no preço do petróleo. É importante frisar que a atual queda do preço do barril atinge outros adversários dos EUA, além da Rússia, tais como Irã e Venezuela.

\section{A financeirização do petróleo}

Desde a década de 1970 do século XX, o mercado financeiro passou a ter influência crescente sobre os preços da commodity aqui analisada. No início do processo denominado pela literatura de financeirização do petróleo, havia uma relação estreita entre o dólar e o petróleo, período no qual os preços desse recurso variavam inversamente com o valor da moeda norte-americana. Durante os períodos de turbulência econômica os agentes buscavam segurança recorrendo ao dólar. No entanto, quando a crise atingia a própria moeda norte-americana, a corrida era em direção às commodities, especialmente ao petróleo, o qual era visto como uma forma de proteção contra a fragilidade do dólar e contra os riscos de inflação. Desse modo, enquanto o valor do dólar caía em comparação a outras moedas, o do petróleo subia, devido à enorme demanda que caracterizava seu mercado (YERGIN, 2014). Nesse aspecto, conforme foi ressaltado na seção anterior, o fim da conversibilidade do dólar e adoção do regime de câmbio flutuante e, consequentemente a derrocada do sistema de Bret-
11. Tal aliança remonta ao ano de 1943, quando o Presidente norte-americano Roosevelt declarou que a Arábia Saudita representava área vital para a segurança do país e assentiu em oferecer auxílio econômico aos sauditas. Tal decisão ocorre justamente no ano em que expiraria a concessão de extração à Standard Oil of California (SOCAL) na Arábia Saudita. "Em 1944, a SOCAL se uniu à Texas Oil Company (TEXACO), que já atuava secundariamente em alguns países da Ásia, e ambas fundaram sua subsidiária na Arábia Saudita com o nome de Arabian-American Company (ARAMCO), que se tornaria um dos principais vetores nas relações norte-americano-sauditas" (NETO, 2013, p. 231). Cabe observar que em 1980, 0 governo saudita resolve nacionalizar a ARAMCO, todavia, tal evento não abalou a relação entre os dois países, pois o processo obteve a anuência dos executivos da empresa e do governo norte-americano. 
12. De acordo com Silvério (2012, p. 18) "os petróleos Brent (Mar do Norte) e WTI (EUA) tornaram-se as principais referências para as fórmulas de precificação do petróleo ao redor do mundo". Além desses dois tipos de petróleo, há também o petróleo tipo Dubai, mas, trata-se de um petróleo com menor volume de negociações no mercado futuro. ton Woods, deram ensejo à financeirização que caracteriza o capitalismo contemporâneo (SERRANO, 2005).

Cumpre ressaltar uma alteração importante no mercado de petróleo em relação ao que ocorria no passado, quando a OPEP representava figura central no processo de fixação do preço do barril de petróleo. Desde 1987, tal organização não mais tem essa função, o que facilitou e/ ou permitiu que o processo de financeirização ocorresse na prática nesse mercado. No bojo desse processo, a comercialização de contratos futuros de petróleo vem crescendo desde então. Um contrato futuro é o compromisso de comprar e/ou vender determinado ativo em uma data específica no futuro, a preços previamente estabelecidos. Eles são negociados em bolsas organizadas e tem suas características padronizadas por essas associações. Esse tipo de contrato pode ser utilizado com o intuito de reduzir riscos de compra e/ou venda de produtos (ou ativos) que possuem alta volatilidade em seus preços, a fim de evitar ou diminuir perdas. Além disso, um contrato futuro também pode servir como meio de especulação, aumentando a exposição ao risco na expectativa de obter lucros (MENDES, 2003).

O objetivo do mercado de futuros é assegurar o preço de compra ou venda de um bem no futuro para proteger o comprador/vendedor de possíveis altas/baixas nos preços desse bem. Assim, salta aos olhos sua aderência ao mercado petrolífero, setor caracterizado pela alta instabilidade nos preços. Por se tratar de um mercado que embute altos riscos associado à volatilidade do preço do petróleo (decorrente de eventuais choques de oferta e demanda e suscetível a eventos geopolíticos), o mercado de futuros no setor petrolífero tem se expandido a taxas significativas (MENDES, 2003; YERGIN, 2014).

Atualmente, em relação aos contratos futuros atrelados ao petróleo, existem duas referências: o West Texas Intermediate (WTI) e o Brent ${ }^{12}$. O WTI (West Texas Intermediate) é negociado nos Estados Unidos, na New York Mercantile Exchange (Nymex), enquanto o Brent é comercializado na bolsa Intercontinental Exchange (ICE). Conforme destacado, os anos 1980 marcam o início da realização de contratos futuro envolvendo petróleo. Desde então, a realização de negócios apoiados em derivativos de petróleo vem crescendo continuamente (MENDES, 2003). A dimensão desse mercado é destaca no relatório da Empresa de Pesquisa Energética (EPE, 2008, p. 31):

\footnotetext{
(...) verificou-se no mercado um aumento drástico nas transações envolvendo papéis de petróleo nos últimos anos. A relação de papéis de petróleo negociada no NYMEX para cada barril de petróleo vendido no mercado aumentou de 6 para 18 nos últimos cinco anos. Em outras palavras, pode-se dizer que no início de 2008 já exista para cada barril "físico" de petróleo negociado o volume de 18 barris "de papel" no mercado de futuro.
}

Assim, não é de se estranhar a volatidade do preço de uma commodity cujo mercado é extremamente suscetível a questões geopolíticas e alterações bruscas na oferta (atrelada a novas descobertas como o pré-sal brasileiro, controle da oferta por parte dos países da OPEP e desastres naturais paralisando a produção em reservatórios em alto mar). As incertezas em torno das cotações futuras representam terreno fértil à demanda especulativa no mercado futuro, visto que o especulador toma decisões 
no presente a partir da previsão que faz sobre a escassez ou abundância no futuro, utilizam estratégias de arbitragem de preços para alcançar o maior lucro possível em suas operações. Nesse contexto, com o aumento da demanda especulativa no mercado futuro, cria-se um cenário no qual o mercado a vista, ou seja, o preço do petróleo a vista, passa a sofrer influência dos movimentos no mercado futuro.

O gráfico 6, ilustra o crescimento (exponencial) observado nos contratos futuros de barris de petróleo Brent negociados na bolsa Intercontinental Exchange (ICE).

Gráfico 6 - Número de contratos futuros de óleo tipo Brent (2000 - 2015)

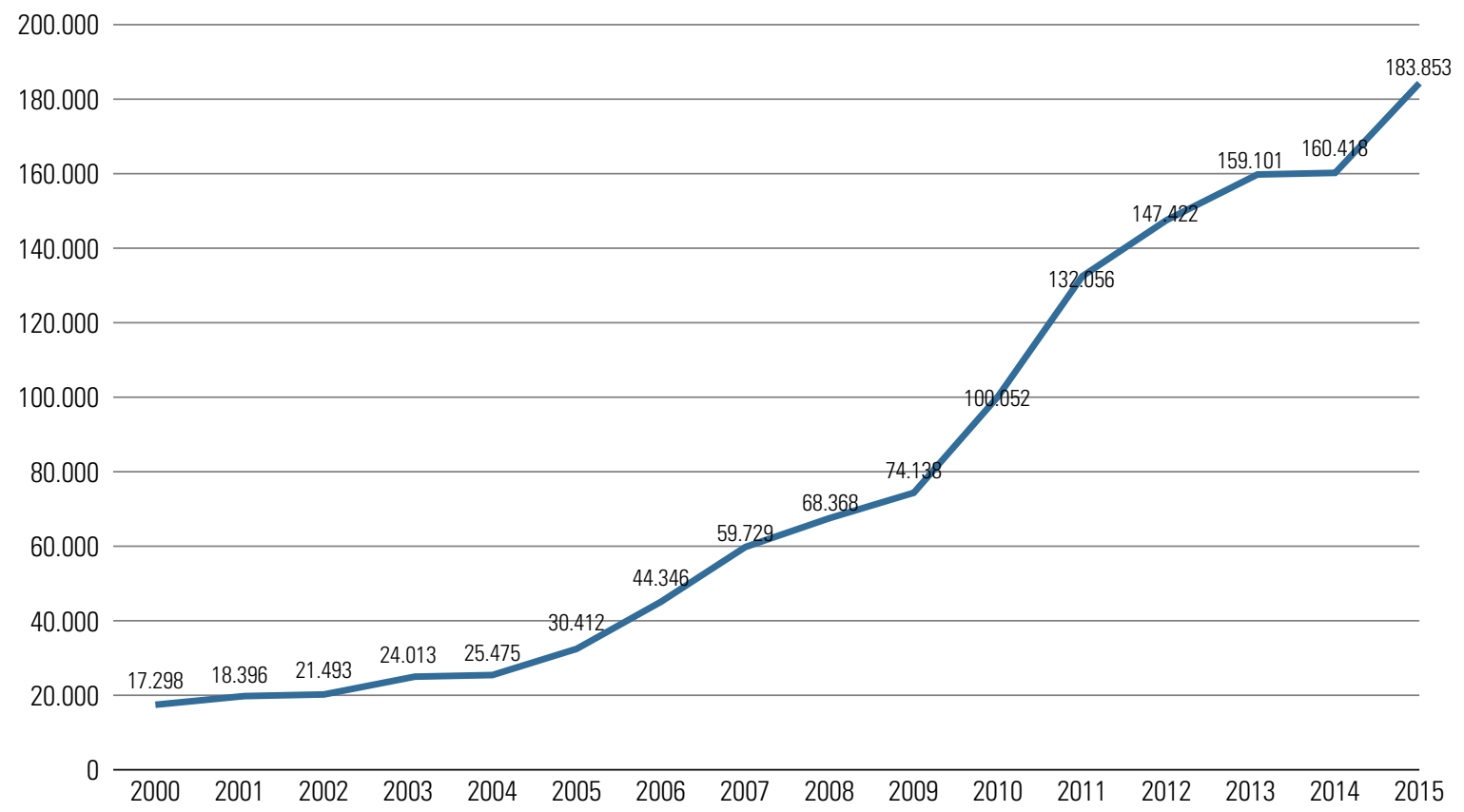
Fonte: ICE (2017).

De acordo com os dados apresentados no gráfico 6, entre 2000 e 2015, houve um crescimento da ordem de cerca de $960 \%$. Assim como em todos os mercados financeirizados da economia mundial, a atuação dos especuladores no mercado de petróleo afeta o preço do barril. O comportamento desses agentes pode gerar, por exemplo, a formação de estoques e, consequentemente, uma dinâmica de retroalimentação. Isso se dá quando os especuladores, buscando ganhar com oportunidades de preço, aumentam o nível de estoque mundial de petróleo por meio da compra do recurso no mercado à vista, para que possam vender no futuro a um valor mais elevado. Essa elevação no nível de estoques pode ser interpretada pelos agentes como um sinal de excesso de oferta, culminando em uma maior redução dos preços à vista, incentivando um novo aumento do volume estocado e gerando um ciclo vicioso de queda nos preços. Tal processo pode agravar ainda mais um patamar de preços que, naturalmente, já se encontra em baixos níveis (ANP, 2015).

Blas (2012) chama a atenção para o fato de que dois anos antes do início do contrachoque abordado neste artigo, os contratos futuros de petróleo, para entrega nos próximos anos, estavam sendo negociados com o maior deságio já registrado comparativamente aos preços spots. O preço 
do petróleo no mercado à vista, do início de 2012 até março do mesmo ano, subiu cerca de US\$ 20. Com tal elevação, o preço do barril (Brent) chegou ao patamar de US\$125,54 no final do mês de março. Ao longo do mesmo período, o preço do mesmo barril no mercado futuro (para entrega em dezembro de 2018) subiu somente US\$ 1, alcançando aproximadamente o valor de US\$95. Esse deságio, superior a US\$ 30 entre o preço físico (ou a vista) e o contrato de cinco anos, foi o maior entre os dois preços (spot e futuro) desde então.

Em virtude da financeirização do petróleo, é possível afirmar que sistema de preços de petróleo se apoia não somente nas transações físicas dessa commodity, como também das posições no mercado futuro. Assim, ainda que se considere o papel representado pela oferta versus demanda, bem como pela geopolítica do petróleo muitas vezes marcada pela turbulência, a alta volatilidade do preço evidencia a importância do jogo financeiro sobre a determinação do preço do petróleo a vista.

Cabe ressaltar a existência de estudos apoiados em análises econométricas os quais sustentam a tese de que o mercado futuro de petróleo e o mercado à vista (ou spot) são estreitamente associados. Oliveira e Salles (2013), com base em análises econométricas se debruçam sobre a relação de longo prazo entre o mercado físico e os contratos futuros de petróleo e chegam a uma conclusão que corrobora a hipótese de cointegração e relações causais entre os preços spot e futuros dos petróleos do tipo Brent. Com base nos dados apresentados os autores destacam que há um alto poder preditivo dos contratos futuros no comportamento de seu mercado à vista. Assim, com a financeirização do petróleo e o aumento no volume de vendas de contratos futuros, argumenta-se aqui que o valor desses contratos passa a exercer influência nas cotações do mercado físico, ou seja, que as posições no mercado futuro contaminam o comportamento dos preços no presente.

Considerações finais

O estudo da geopolítica do petróleo no século atual se revela de grande importância tendo em vista que, mesmo com o surgimento de novas fontes energéticas, o papel que esse recurso ainda detém dentro da matriz de energia do mundo é de escala primordial. Seja para a segurança energética, para o desenvolvimento ou mesmo para o sustento econômico dos países, o interesse pelo domínio desse bem parece se reafirmar e se fortalecer cada vez mais.

Muitas forças atuam no mercado de petróleo afetando o sistema de preços dessa commodity no mercado internacional. As tendências de oferta e demanda, em se tratando de tal riqueza, não se comportam de forma livre e natural, de modo que, muitas vezes, o que estão em jogo são os interesses por detrás das estratégias aplicadas por diversos atores cujos objetivos econômicos e políticos encontram no petróleo um papel principal. Isso acaba gerando um comportamento ainda mais instável dos preços dessa commodity, o qual se comprova quando analisamos o tabuleiro da geopolítica do petróleo no século XXI.

A geopolítica do petróleo no século XXI conta com novos atores e estratégias, o que aumenta o número de variáveis a serem analisadas. En- 
quanto no século $\mathrm{XX}$ os países exportadores comandavam as políticas de produção e de estabelecimento de preços, nos dias atuais não se percebe essa rigidez, tendo em vista o crescimento do número de concorrentes. Portanto o tema do petróleo envolve uma inegável inter-relação entre economia, geopolítica e relações internacionais, evidenciando o fato de que o petróleo, para além de questões de energia, representa força e poder político e econômico no cenário internacional. Ademais, conforme discutido neste artigo, desde o fim do século passado, o petróleo se transformou em um recurso com caráter de ativo financeiro, à mercê de atitudes especulativas e vítima de maior volatilidade. Nesse sentido, o ouro negro, assim como outras commodities, tem seu preço também influenciado pelos movimentos no mercado financeiro.

Nesse sentido, as oscilações no preço do petróleo (algumas vezes abruptas, como ocorreu recentemente) não podem ser analisadas apenas e tão somente à luz das variações na oferta e na demanda. É preciso que sejam descortinados os principais movimentos das peças da geopolítica do petróleo, bem como, do papel desempenhado pelo mercado futuro na formação do preço a vista (ou seja, influencia do mercado financeiro). É claro que esses elementos não são estanques, na verdade, como foi dito, eles se interpenetram, estão inter-relacionados, há retroalimentações entre eles.

Assim, considerando todos esses elementos que interferem e sofrem a interferência do preço do barril do petróleo (em um processo de retroalimentação), é possível destacar os seguintes elementos que contribuem com o desencadeamento do contrachoque atual: $1^{\circ}$ ) a alta no preço que antecedeu o contrachoque, incentivou o aumento da produção; $2^{\circ}$ ) o desaquecimento da economia global, desfavoreceu o crescimento no consumo; $3^{\circ}$ ) o ampliação da capacidade mundial de refino, não acompanhada pelo consumo, desencadeou a geração de estoques; $4^{\mathrm{a}}$ ) a revolução do fracking norte-americano e o avanço na produção dos hidrocarbonetos não convencionais; $5^{\mathrm{a}}$ ) o enfraquecimento do papel da OPEP, como entidade reguladora do preço do barril de petróleo; $6^{a}$ ) a estratégia saudita, de manutenção de sua produção em patamares elevados, para atingir o fracking norte-americano e o Irã; $7^{\mathrm{a}}$ ) a rivalidade entre Rússia e Arábia Saudita, explicando a postura russa de não reduzir sua produção mesmo diante da queda no preço do petróleo a partir de 2014; $8^{\mathrm{a}}$ ) o término do conflito e os esforços de reconstrução trazendo de volta ao mercado os principais fornecedores de petróleo da Líbia, Argélia e Iraque; $9^{a}$ ) a assinatura do acordo nuclear e o fim do embargo ao Irã, permitindo que o país reocupasse parte do mercado bloqueado antes do acordo; $10^{\circ}$ ) o fator mercado financeiro: o aumento no volume dos contratos futuros de petróleo interferindo na formação do preço à vista.

Ainda que essa lista não esgote todas as variáveis que provocam oscilações no preço do barril de petróleo, ela comprova que os mecanismos formais da oferta e demanda - largamente adotados em estudos sobre esse tema - são insuficientes para dar conta da complexidade e da miríade de fatores que influenciam o sistema de preços no mercado de petróleo. Assim, a principal contribuição deste artigo para estudos acerca do fenômeno de flutuações no preço do petróleo é a ideia de que estamos diante 
13. Em outubro de 2016 a Câmara dos Deputados derrubou a obrigatoriedade da Petrobras na exploração do pré-sal. de um processo histórico e dialético complexo, retroalimentado pela própria produção, pelo poder das nações (produtoras e consumidoras) e pelas finanças internacionais.

Por fim, apesar de não ser o foco deste artigo, cabem algumas reflexões sobre a inserção do Brasil na geopolítica do petróleo, sobretudo após a descoberta do pré-sal. Em um primeiro momento a descoberta do pré-sal foi vista como símbolo do sucesso da Petrobras, além de "bilhete premiado", com o qual o Brasil poderia alavancar seu desenvolvimento industrial, tecnológico, econômico e social. Todavia, tal descoberta, ao mesmo tempo em que colocou novas oportunidades ao Brasil, despertou interesses de outros países. Telegramas do consulado dos Estados Unidos no Rio de Janeiro, obtidos e divulgados pelo WikiLeaks, datados entre janeiro de 2008 e dezembro de 2009, revelam a preocupação da diplomacia norte-americana com o marco regulatório do pré-sal. Nesses documentos é explicitada a preocupação das autoridades norte-americanas pelo fato do marco legal criado pelo governo brasileiro ter colocado a Petrobras como operadora-chefe dos projetos localizados no novo cluster (WIKILEAKS, 2009).

Assim, há fortes indícios de que os Estados Unidos atuaram nos bastidores, para alterar o marco regulatório do pré-sal ${ }^{13}$ reduzindo o protagonismo da Petrobras materializada no marco regulatório do pré-sal aprovado no governo Lula, desestabilizar o Brasil politicamente via operação Lava Jato. No que diz respeito à operação Lava Jato, é possível considera-la como uma das forças que minou politicamente a ex-Presidenta Dilma Rousseff, abrindo espaço à aprovação do impeachment, além de trazer importantes abalos na relação entre a estatal brasileira e a cadeia de fornecedores doméstica.

Portanto, como agenda para estudos futuros, dada a importância do tema, cabe um maior aprofundamento na discussão em torno da inserção do Brasil na geopolítica do petróleo após a descoberta do pré-sal.

Referências

AGÊNCIA NACIONAL DO PETRÓLEO, GÁS NATURAL E BIOCOMBUSTÍVEIS (ANP). Boletim Anual de Preços 2015: preços do petróleo, gás natural e combustíveis nos mercados nacional e internacional / Agência Nacional do Petróleo, Gás Natural e Biocombustíveis. Rio de Janeiro: ANP, 2015.

BARROS, E. V. "A matriz energética mundial e a competitividade das nações: bases de uma nova geopolítica", Engevista. Rio de janeiro, v. 9, n. 1, p. 47-56, 2007 a.

BARROS, P. S. Venezuela: mudanças e perspectiva - a razão chavista. In: CARMO, C.A.; BARROS, P.S.; MONTEIRO, L.V., Venezuela: Mudanças e Perspectiva. Brasília: Fundação Alexandre de Gusmão, 2007b.

BLAS, J. Preço futuro do petróleo indica queda para menos de US\$ 100. Folha de São Paulo, 28 mar. 2012. Disponível em:< http://www1.folha.uol.com.br/fsp/mercado/33868-preco-futuro-do-petroleo-indica-queda-para-menos-de-us-100.shtml> Acesso em: 11 abr. 2018.

BRITISH PETROLEUM (BP). BP Statistical Review of World Energy, June 2016. London: BP, 2016.

EBEL, R. E. (2002). Discurso na abertura do Open Forum: Geopolitics of Energy into the 21st Century, Washington (DC), 30 abr. de 2002. Disponível em: <http://2001-2009.state.gov/s/p/ of/proc/tr/10187.htm> Acesso em 04 mai. 2016.

EMPRESA DE PESQUISA ENERGÉTICA (EPE). Contexto mundial e preço do petróleo: uma visão de longo prazo. Documento Técnico. Dezembro de 2008. Disponível em http:// www.epe.gov.br/Petroleo/Documents/Estudos_29/Contexto\%20Mundial\%20e\%20Preço\%20 do\%20Petróleo\%20Uma\%20Visão\%20de\%20Longo\%20Praz o.pdf >. Acesso em: 23 set. 2017. 
ENERGY INFORMATION ADMINISTRATION (EIA). Annual Energy Outlook 2016. Disponível em: <https://www.eia.gov/outlooks/archive/aeo16/pdf/0383(2016).pdf > Acesso em: 25 mai. 2016.

ENERGY INFORMATION ADMINISTRATION (EIA). Hydraulic fracturing accounts for about half of current U.S. crude oil production. Disponível em: < https://www.eia.gov/todayinenergy/detail.php?id=25372 > Acesso em: 07 abr. 2017.

FUSER, I. O petróleo e o envolvimento militar dos Estados Unidos no Golfo Pérsico (1945 2003). São Paulo, 2005. 330f. Dissertação (Mestrado em Relações Internacionais) - Programa de Pós-Graduação em Relações Internacionais "Santiago Dantas", da Universidade Estadual de São Paulo (Unesp), Pontifícia Universidade Católica de São Paulo (PUC-SP) e Universidade Estadual de Campinas (Unicamp).

GHIRARDI, A. G. Petróleo: a virada nos mercados globais e o pré-sal. Carta Capital, 17 nov. 2014. Disponível em: < https://www.cartacapital.com.br/blogs/outras-palavras/petroleo-a-virada-nos-mercados-globais-e-o-pre-sal-8281.html> Acesso em 11 abr. 2017.

HALLIGAN, L. Geopolitics of oil takes new twist with Saudi-Russia deal. The Telegraph - Business. Disponível em: < http://www.telegraph.co.uk/business/2016/02/21/geopolitics-of-oil-takes-new-twist-with-saudi-russia-deal/> Acesso em 05 jun. 2016.

INTERCONTINENTAL EXCHANGE (ICE). Report center. Disponível em: < https://www. theice.com/marketdata/reports/7>. Acesso em: 23 set. 2017.

ISENMANN. A. F. Fracking. Centro Federal de Educação Tecnológica de Minas Gerais, Timóteo, 2014. Disponível em: <http://www.timoteo.cefetmg.br/site/sobre/cursos/quimica/repositorio/artigos>. Acesso em: 26 out. 2014.

KLARE, M. There will be blood: political violence, regional warfare and the risk of greatpower conflict over contested energy sources. In: LUFT, Gal; KORIN, Anne (eds). Energy Security Challenges for the 21 st century. Santa Barbara: ABC-CLIO, 2009.

LIMA, J. A. O petróleo despenca, e a Arábia Saudita sorri. Carta Capital - Internacional. 07 jan. 2015. Disponível em: < http://www.cartacapital.com.br/internacional/o-petroleo-despenca-e-a-arabia-saudita-sorri-3244.html> Acesso em 29 jul. 2016.

LINS, H. N. Geoeconomia e geopolítica dos recursos energéticos na primeira década do século XXI. In: $3^{\circ}$ ENCONTRO NACIONAL ASSOCIAÇÃO BRASILEIRA DE RELAÇÕES INTERNACIONAIS, 2011.

MENDES, A. F. Mercado futuro de petróleo: origem e desenvolvimento. Monografia em Economia - Universidade Federal do Rio de Janeiro, Instituto de Economia, Rio de Janeiro, 2003.

PINTO JR., H. Q. e FERNANDES, E. S. L. O mercado internacional do petróleo e o comportamento dos preços. Nota Técnica n ${ }^{\circ} 02 / 98$. Agência Nacional do Petróleo, mimeo. Rio de Janeiro, 1998.

PINTO JR., H. Q. et al (Orgs.). Economia da energia: fundamentos econômicos, evolução histórica e organização industrial. 1. ed. Rio de Janeiro: Campus, 2007.

RAFAEL, J. M. C. A estratégia energética da Rússia. O caso do gás natural nas relações com a Europa. Lusíada. Política Internacional e Segurança, n. 9, 2013. Disponível em: <http://revistas. lis.ulusiada.pt/index.php/lpis/article/view/431/410>. Acesso em: 8 out. 2016.

RAMONET, I. A nova geopolítica do petróleo. Outras Palavras, 14 jun. 2015. Disponível em: $<$ http://www.ihu.unisinos.br/noticias/543565-ignacio-ramonet-a-nova-geopolitica-do-petroleo> Acesso em 29 abr. 2016

SERRANO, F. Relações de poder e a política macroeconômica americana, de Bretton Woods ao padrão dólar flexível. In: Fiori, J. L. O Poder Americano. Petrópolis: Vozes, 2004.

SILVÉRIO, R. P. O papel da esfera financeira no processo de determinação dos preços do petróleo no mercado internacional: uma análise de price discovery dos mercados Brent $\mathrm{e}$ WTI no período 1990-2011. Rio de Janeiro, 2012. 119f. Dissertação (Mestrado em Planejamento Energético) - Programa de Pós-graduação em Planejamento Energético, COPPE, da Universidade Federal do Rio de Janeiro.

THE GUARDIAN. The Guardian view on the geopolitics of falling oil prices. The Guardian, Editorial, 13 jan. 2016. Disponível em: < https://www.theguardian.com/commentisfree/2016/ jan/13/the-guardian-view-on-the-geopolitics-of-falling-oil-prices $>$ Acesso em 05 abr. 2017.

TORRES FILHO, Ermani T. O papel do Petróleo na Geopolítica Americana. 2004. pg. 181-230. In: Conferência Nacional de Política Externa e Política Internacional-II CNPEPI : (2 : Rio de Janeiro : 2007). Seminário Estados Unidos: presente e desafios. — Brasília: Fundação Alexandre de Gusmão, 2008. 
(ei) estudos internacionais • Belo Horizonte, ISSN 2317-773X, v.6 n.1 (2018), p.87 - 106

WIKILEAKS. Can the oil industry beat back the pre-salt law? Disponível em: < https://wikileaks.org/plusd/cables/09RIODEJANEIRO369_a.html> Acesso em 29 abr. 2016.

YERGIN, D. O Petróleo - Uma História de Ganância, Dinheiro e Poder. 3. ed. São Paulo: Scritta, 1993.

YERGIN, D. A busca: energia, segurança e reconstrução do mundo moderno. Rio de Janeiro: Intrínseca, 2014.

YERGIN, D. Oil prices are at the mercy of geopolitics. Finantial Times. 20 jan. 2016. Disponível em: $<$ https://www.ft.com/content/5c6e1840-bed2-11e5-9fdb-87b8d15baec2> Acesso em 05 abr. 2017. 